\title{
Doping control in professional football
}

The World Cup finals in France are eagerly awaited by players and fans alike. For the players participation represents the pinnacle of their career, and hopefully the tournament will be remembered for the skill and excitement generated by these exceptional athletes. Possibly, however, the tournament may be marred by the detection of drug abuse in some competitors and the adverse publicity that this will generate.

Doping control in professional football in the United Kingdom is carried out by the Football Association (FA) in conjunction with the Sports Council, in line with the regulations of the International Olympic Committee. ${ }^{1}$

The FA doping control programme was introduced in the 1990-91 season, with sampling being restricted to competitive matches only. For the $1994-5$ season the programme was extended to include out of competition unannounced testing at training grounds, random and designated targeting of players at all levels from youth (age 9-18) at FA centres of excellence, Youth Training Scheme, and women players. As of the 1995-96 season alcohol breath testing has been added to the FA programme as part of continuing monitoring. Detection of excess alcohol does not of itself warrant a charge of misconduct, but were a player to be found guilty of misconduct on the field, and found to have had an excessive level of alcohol at the time, then the alcohol would be considered to have been an aggravating factor in his behaviour.

The prime function of the FA doping control programme is to protect the physical wellbeing and health of the players and the integrity of the sport, and should not be considered simply as a punitive tool. To this end an extensive education programme takes place which targets players at all levels. Children attending centres of excellence and their parents are given information packs, which discuss the hazards of drug abuse in sport and in society in general. In addition, heavy emphasis is placed on providing education about diet and appropriate training techniques, which make the consideration of performance enhancing drugs unnecessary. This approach is reinforced by coaching staff at all levels, the coaches themselves being similarly educated about these issues.

Many positive finds are due to substances that occur in popular over the counter medicines, or have been inadvertently prescribed to players by doctors unaware of the doping regulations. It has been shown that general practitioners' knowledge of prohibited substances in sport is poor. ${ }^{2}$ In that survey it was shown that only $53 \%$ of GPs were aware of the Sports Council guidelines in the British National Formulary, and that $12 \%$ believed that medical practitioners were allowed to prescribe anabolic steroids for non-medical reasons. It is the responsibility of the professional club medical teams to brief players annually on the regulations and to encourage them to advise all medical practitioners whom they may consult of the doping regulations. In addition, each player is provided with a credit card sized reference which outlines the classes of banned substances, and gives examples of banned and permitted drugs for several common illnesses.

Some substances - for example, local anaesthetics and corticosteroids, either inhaled or ingested, are permitted for approved treatment. ${ }^{3}$ It is the responsibility of the doctor prescribing these substances, however, to inform the FA doping control centre of the administration of such drugs to players. Table 1 shows the number of positive tests for
Table 1 Positive tests for performance enhancing and social drugs over several seasons

\begin{tabular}{llc}
\hline Season & Tests performed & Positive finds \\
\hline $1992-93$ & 100 & 0 \\
$1993-94$ & 272 & 12 \\
$1994-95$ & 272 & 7 \\
$1995-96$ & 500 & 5 \\
\hline
\end{tabular}

performance enhancing drugs and social drugs over the past few seasons.

During the current season more than 500 tests have been carried out to date, with only three positive finds. It is encouraging that the trend is downwards and hopefully with continuing education this will continue to be the case. In two cases where performance enhancing drugs were detected it was proved that the player had ingested "spiked" drinks while out socially, and these incidents resulted in police investigations.

When a player tests positive for prohibited substances he or she will be subject to disciplinary proceedings at the FA, but before this happens there will be an opportunity to explore any mitigating reasons for the positive test. This is not carried out in isolation and the player will be offered help with counselling and any appropriate rehabilitation.

It is difficult to see any great advantage to football players in using performance enhancing drugs. The game requires both aerobic and anaerobic capacity, coupled with intermittent explosive work, agility, and fine coordination. Excessive body mass is a hindrance, and as a large number of games are played over a season it is impossible to know when peaks of performance are required. For the successful player consistent performance is by far the greater requirement, and this can be achieved only by appropriate training and nutrition. Hardy et al concurred with this view after reviewing the results of 900 tests carried out in Australian Rules Football-no cases of the use of performance enhancing drugs were detected. ${ }^{4}$ In addition, Yeater et al showed that equivalent improvements in cardiorespiratory parameters and body composition could be achieved with resistance training with or without the use of anabolic steroids. ${ }^{5}$

With the ever increasing problems of drug abuse in society the greater risk to player's health and fitness may come from social drugs. Although it is easy to justify testing for banned substances which give the athlete an unfair advantage, testing for social drugs and alcohol has implications for the freedom of the individual, particularly when some clubs test players of their own accord for internal disciplinary reasons. The FA actively discourages testing by individual clubs. It is important, however, to test for these substances as their use may adversely influence the behaviour of players on the field, with resultant injury to themselves or others.

Players are aware they will be tested for social drugs as part of the national programme, and if these are detected they will be offered counselling and rehabilitation, together with continuing education. The testing of players below the age of 16 also raises certain ethical issues-no test is carried out without the prior written consent of the parents. Goldberg et al showed that education of young collegiate football players positively enhanced healthy behaviour and turned their approach towards achieving greater fitness from appropriate training techniques and away from drug use. ${ }^{6}$ This philosophy of prevention through education underpins the doping control programme in professional football in the United Kingdom. It 
is designed to ensure that future generations of young players will be aware of the dangers of drugs of all classes, and will be equally aware of the benefits of appropriate nutrition and training in achieving high performance standards.

ANDREW R DENT

Sports Physician

19 Sandon Avenue

Westlands

Newcastle

Staffordshire ST5 3QB
1 Dirix A, Knuttgen HG, Tittel K. The Olympic book of sports medicine. Vol 1. Oxford: Blackwell Scientific, 1988.

2 Greenway P, Greenway M. General practitioner knowledge of prohibited substances in sport. Br f Sports Med 1997;31:129-31.

3 Harries M, Williams C, Stanish WD, et al. The Oxford textbook of sports medicine. Oxford: Oxford University Press, 1994.

4 Hardy KJ, McNeill JJ, Capes AG. Drug doping in Senior Australian Rules football: a survey for frequency. Brf Sports Med 1997;31:126-8.

5 Yeater R, Reed C, Ullrich I, et al. Resistance trained athletes using or not using anabolic steroids compared to runners: effects on cardiorespiratory variables, body composition and plasma lipids. $\mathrm{Br} F$ Sports Med 1996;30:11-14.

6 Goldberg L, Elliot D, MacKinnon DP, et al. Effects of a multidimensional anabolic steroid prevention intervention. The Adolescents Training and Learning to Avoid Steroids (ATLAS) Program. $\mathcal{F A M A}$ 1996;276:1555-62.

\section{"Will common sense prevail?"}

Just before the World Cup in the United States in 1994, Northern Ireland played a friendly international against Mexico in Miami, in mid-afternoon temperatures approaching $100^{\circ} \mathrm{F}\left(38^{\circ} \mathrm{C}\right)$. Players were told by the referee that they could drink fluids during the game only if they came off the pitch at the halfway line. Naturally neither the players nor the manager were keen to leave the pitch during play. During every natural break in play, such as a throw in, we tried to get as many water bottles onto the pitch as possible. Early in the game, however, the referee banned us from continuing with this practice. Similarly, when we tried to distribute water bottles during breaks when injuries were being treated, the team doctor (me!) was banned from coming onto the pitch! FIFA's directive to referees to eliminate time wasting by players seemed to be taking precedence over common sense. While the climatic conditions in France this summer will not be as extreme as four years ago, perhaps this guideline should be amended to allow the referee to exhibit a degree of judgment.

A similar situation can arise during the initial treatment of an injured player, when they are bundled onto the "body wagon" by paramedics and driven off the pitch before the medical staff can make a reasonable assessment of the injury. The player often jumps off the cart as soon as it has reached the sideline and signals to be allowed back on (causing a further delay before the game can be restarted). It is interesting that the official UEFA technical report on "Euro 96" noted that this guideline may have to be altered. While we all welcome measures to limit time wasting, occasionally they may place the genuinely injured player at risk.

MICHAEL CULLEN Medical Adviser Irish Football Association 